\title{
Students' desires for high-level teaching and learning opportunities: Views of Namibian Grade 11 students observed to have difficulties in learning mathematics
}

\author{
Shemunyenge Taleiko Hamukwaya
}

\begin{abstract}
This study focusses on the views of students in learning grade 11 mathematics in terms of their needs and aspirations regarding access to high-level mathematics teaching and learning opportunities. Students who participated in this study ( 88 grade 11 Namibian students) were identified as having learning difficulties by their mathematics teachers, but these students did not (themselves)consider that they had difficulties. The author attempts to understand why students believed they do not have difficulties in learning mathematics. A qualitative method was employed, and the students were investigated via semi-structured interviews. The transcripts were analysed using an interpretational analysis. This study revealed that students display interest in learning mathematics and that they tend to feel comfortable with the subject despite certain influencing factors. The students' perceptions are that their learning processes were negatively affected by aspects of systemic factors, teachers' and students' own factors, and access to learning resources. The students feel that they lack high-level access to teaching and learning, and this limits their potential for achieving the level at which they are expected to perform and be academically successful. In addition to the implications that emerged, this study makes recommendations on what should be done to address the negative factors perceived by the students.
\end{abstract}

Keywords: students' desires, students' views, learning mathematics, learning difficulties, learning opportunities

\section{Introduction}

Mathematics is a core school subject in many countries due to its importance in achieving better lives for individuals and society at large (Ampandu, 2013; Anthony et al., 2012; Gafoor \& Kurukkan, 2015; Mundia, 2010). In Namibia, mathematics is a compulsory subject for $\mathrm{K}-12$ school. It is considered an entry requirement for various careers such as the natural sciences, engineering, medicine, and architecture (Ampandu, 2013; Keith, 2000; Siyepu, 2013). This indicates that mathematics is a base for all scientific and technological studies, with a thematic link to other subjects across the curriculum (Mundia, 2010). A general perception surrounding mathematics is that achieving good results in mathematics serves as an adequate measure for entering an institution of higher learning and being accepted into a good programme (Ampandu, 2013). However, according to Agudelo-Valderrama (1996), most students do not achieve good grades in mathematics, making it difficult for them to be admitted at institutions of higher learning.

The contributing factors associated with having difficulties in learning mathematics in high school in the Namibian context are not fully known; therefore, in this study, the author attempts to examine and understand the views of grade 11 students studying an ordinary mathematics curriculum (core and extended-level). However, during the interviews, these students revealed that they themselves do not believe they were having difficulties. Though the students

\footnotetext{
${ }^{1}$ Shemunyenge Taleiko Hamukwaya (Ms.), Department of Mathematics and Statistics, Faculty of Mathematics and Natural Science, University of Turku. Email: shtaha@utu.fi; Phone+358403261055

Open Access article distributed under the terms of the Creative Commons Attributions License [CC BY-NC-ND 4.0] http://creativecommons.org/licenses/by-nc-nd/4.0. DOI: https://dx.doi.org/10.4314/ajesms.v16i1.2
} 
Students' desires for high-level teaching and learning opportunities: Views of Namibian

Grade 11 students observed to have difficulties in learning mathematics

S. T. Hamukwaya

recognised that they were not successful in mathematics, they did not believe it was because they were having difficulties in learning mathematics, as they felt comfortable with the subject despite the influencing factors. Students refused to accept their teacher's assessment, as they perceived that their surroundings were inherently unfair and did not contribute to their success in mathematics. Why do such discordant views exist in the minds of students? The evidence concerning the differing views between teachers and their students was a key factor in the decision to examine students' views in this paper.

This study contributes to the overall studies performed in the field of mathematics education, particularly those on students' views and their teaching and learning. The study illustrates that students may have been identified as experiencing difficulties in learning mathematics but may themselves possess positive views and a clear desire to learn mathematics. However, much research needs to be conducted on students' views but the work thus far has yielded important findings (e.g. Ponte et al., 1994; Roesken et al., 2011). No literature was found that unpacked students' views using the approach in this study. Based on the findings reported in this paper, students themselves did not accept that they were having difficulties in learning mathematics. Furthermore, this study reports qualitative findings from a large sample representing four Namibian educational regions, and most earlier studies have relied on small samples. Moreover, the limited amount of available research conducted in an African context and the need for better educational outcomes have raised a requirement for more research to examine and understand students' views, thoughts, and opinions regarding learning mathematics. This is particularly true in the Namibian context, which has received little attention from research communities. Thus, this study makes both methodological and practical contributions to the current debate on students' views regarding mathematics. Furthermore, this study adds knowledge particularly to the body of students' views on learning mathematics, and it extends the current knowledge base regarding mathematics education in the African context.

This paper begins by discussing views regarding students and learning mathematics. It then explains the contexts and methods used in this study. Subsequently, the author then describes the results, and finally, a discussion and conclusion of the results in the light of the literature are presented.

\section{Literature review}

In the literature, the term 'views' is discussed in many studies as referring to beliefs (e.g. Stodolsky et al.,1991; Roesken et al., 2011). However, the term is a broad concept that incorporates general aspects of the social learning of mathematics, whereas 'belief' is considered a cognitive concept (McLeod, 1992; Roesken et al., 2011). Views are indispensable in forming and organising the meaning of things, but on the other hand, they can block the perception of new realities and the identification of new problems (Ponte et al., 1994). They shape how students approach mathematical activities and, in many cases, lead students to follow non-productive paths (Ponte et al., 1994). Students have different views, attitudes, and expectations regarding mathematics, and these have been considered the most significant factors underlying their school experience (Schoenfeld, 1985). Nevertheless, Costu et al. (2009) state that the student's attitudes, feelings, and views about mathematics, shape their future academic success and underscore the significance of students' views regarding specific instructional techniques.

\section{Views regarding learning mathematics}

The way mathematics is conceived, taught, and learnt has not only contributed to many students failing to realize their full potential but has also caused most students to not fully comprehend 
the importance of the mathematics they are learning (Agudelo-Valderrama, 1996). Students who do not enjoy learning mathematics often perceive mathematics as an unpleasant (Sedig, 2008), and difficult-to-learn subject (Costu et al., 2009). Furthermore, While, et., al. (1991) found that mathematics is one of the most enjoyed subjects and is rated as highly important at all school levels, but as students' progress from lower grades to higher grades, many find it difficult to learn mathematics (Stodolsky et al., 1991). The content of learning becomes more abstract, and it requires more conceptual understanding (Wong at al., 2001). This might explain why some secondary school students find mathematics to be difficult and perform poorly (Anthony et al., 2012), and this may be a case in Namibia, as well.

Several scholars have studied students' views of mathematics from different perspectives (e.g. Buehl \& Alexander, 2005; De Corte et al., 2002). For instance, Roesken et al. (2011) conducted a study on students' views of themselves as learners of mathematics; they stated that students' views about a subject and its teaching and learning impact their learning. In this paper, the author considers 'view' to be an appropriate aspect of students' social learning situations, and focusses on students' views regarding learning mathematics and the factors that influence students' views.

The literature discusses several factors that influence students' learning of mathematics, including such aspects as the relationship between students and teachers, the learning environment, and systemic factors. According to Tsanwani et al. (2014), those factors considered to form a barrier to proper learning include inadequate teaching and learning facilities, negative practices by teachers, low expectations from students, poor teaching strategies, and a shortage of support from teachers. In addition to this, absences of both teachers and students meaning that insufficient time is spent on the subject; this is one of the systemic factors that affects students' achievement in mathematics (e.g. Fleisch, 2008). Moreover, the content knowledge of teachers and the student's own motivation and interest were also found to be among the factors contributing to poor performance in mathematics and science by high school students (Makgato, 2007).

\section{Students' views}

Studying the views of students regarding their learning mathematics is based on the assumption that they significantly influence students' thinking and learning. According to Roesken et al. (2011), students' beliefs, needs, and feelings are crucial elements regarding their views of themselves as learners of mathematics. The aspect of feelings refers to emotions that students experience while learning mathematics, whereas the aspect of needs is based on human requirements, including the desire for competence (Roesken, et al., 2011). Moreover, the feelings and views regarding the learning of mathematics originate from and are influenced by memories of the students' past failures and successes, social interactions, methods of teaching, the type of mathematics to which they have been exposed, and learning environments (Stodolsky et al., 1991).

The views of students regarding learning mathematics have been considered to be a significant factor that underlies their school experience and achievement (Schoenfeld, 1985; Roesken, et al., 2011). They are particularly appropriate when used to capture affect-cognition interplay in social learning situations, and thus as students' prime source of mathematical experience is the classroom, it is a context which will influence their views and beliefs (Roesken et al., 2011). According to Hoyles (1982), students can feel good about their learning experiences and themselves as learners, and they can express a connection between their feelings and instructional experiences. According to Stodolsky and colleagues, classroom experiences, the subject content and its competencies, the way a subject is presented, and the contexts in which students are located contribute to differences in students' perceptions (Stodolsky et al., 1991). 
Students' desires for high-level teaching and learning opportunities: Views of Namibian

Grade 11 students observed to have difficulties in learning mathematics

S. T. Hamukwaya

This reveals that students' views impact their learning process. Thus, it is important to acknowledge this aspect when students are asked about their views of mathematics with respect to their learning experiences (Roesken et al., 2011).

Roesken et al. (2011) describe seven dimensions of students' views of themselves as learners of mathematics, based on the learning experiences of students in mathematics. Three of the dimensions relate to personal beliefs: ability, effort, and success. Two of the dimensions relate to students support from their teachers and family: teacher quality and family encouragement. Finally, the last two dimensions relate to emotions: enjoyment of mathematics and difficulty with mathematics. In their study, some students believed that learning mathematics requires a specific talent or innate ability. Their findings further reveal that students with positive views consider themselves to be talented in mathematics, and confident of doing well in the future, they perceive mathematics as easy and enjoy the subject. Thus, they found that these dimensional views are crucial and might even form an obstacle for students when they do not feel they are capable of doing mathematics and simultaneously experience mathematics as being very difficult (Roesken et al., 2011).

A Ghanaian study conducted with fifth graders found that some students viewed mathematics as an easy subject and felt successful, whereas other students expressed feelings of difficulty, failure, frustration, lack of success, and anxiety (Stodolsky, et. al., 1991). Their findings further indicated that for students to be successful and learn mathematics on their own, previous skills must first be mastered. Furthermore, they stated that the students believed they cannot learn mathematics on their own and that they require a knowledgeable person to provide assistance (Stodolsky et al., 1991).

The literature reveals that students have different ideas about how to learn school subjects and they express different reasons for their positive and negative experiences as regards their success in mathematics at school (Stodolsky et al., 1991). Providing students with opportunities to express their views and thoughts promotes participation in the teaching and learning process (Boaler, 1998). Moreover, students' views regarding the teaching and learning of mathematics are missing from discussions in the field of mathematics education, especially within the Namibian context. Thus, this paper provides documentation of students' views based on two formulated questions that form a useful framework for addressing the goal of this study:

(a) Why did the teachers identify these students as having difficulties in learning grade 11 mathematics while the students themselves did not?

(b) What are the factors that influence students' views concerning their learning of mathematics?

\section{Method}

This study used a qualitative method to gather information from Namibian grade 11 students. Four regions of Namibia were considered for this study, as they were easily accessible to the researcher. The following is an overview of the methodology approach.

\section{Context}

This study was conducted at 23 Namibian public high schools. In Namibia, the teaching of the content of the high school mathematics syllabus should be completed in two years. During this period, students are exposed to a variety of subjects aimed at meeting their interests; the curriculum also caters to a wide range of students' abilities, including those for students who will continue their studies in mathematics and other disciplines. Students must take a few internal preliminary examinations before registering for their high school final examination. 
The results of these internal examinations provide an indication of the appropriate level at which students should registered for the final examination: ordinary (core or extended) or higher level. The teaching and learning content levels also differ, and mathematics teachers must ensure that students register for the correct option. In some high schools, students with different mathematics options are placed in the same mathematics class, and the teachers must therefore manage the teaching of the various mathematics levels that are present in their classes. However, in other schools, students are grouped into classes based on their previous performance in grade 10.

What is a typical Namibian ordinary mathematics syllabus, and who should study it? As mentioned in the introduction, the context of this study is based on students studying an level mathematics syllabi - both core and extended. The core level of the Namibia syllabus aims to ensure that every student can use numbers with understanding, whereas the extended mathematics syllabus is primarily pure mathematics (e.g. the use of the laws of logarithms, describing functions, and calculating the magnitude of a vector), i.e., the mathematics required by students to fulfil their mathematical potential at the tertiary level. Typically, extended mathematics can be taken by students who achieved a good result in grade 10 additional mathematics, meaning they achieved the best marks ( $70 \%$ or higher) in the examination, while the other students are placed in the core level. In addition, students who achieved $70 \%$ or higher in mathematics at the ordinary level in grade 10 and have the ability to manage the mathematics of the extended syllabus should be given the opportunity to do so. However, many students who achieved the best results in ordinary-level mathematics in grade 10 were not successful at the extended level. Thus, it is likely that most of the Namibian high school students who opt to study the core level have not coped well with the subject in the past. However, the participants reported in this paper were the penultimate students to take this curriculum; the new curriculum was implemented in 2019, as Namibia revises its curriculum every seven years.

\section{Sample}

The total number of students who agreed to participate in the study was 115 . These students were enrolled in grade 11 and were studying ordinary mathematics at the time of the interview, and most opted for the core level. This paper reports the findings from 88 of the students (23 males and 55 females) who did not consider they had difficulties in learning. The findings from the other 27 students, who confirmed during the interview that they were having difficulties in learning mathematics, are reported in a different paper. The students' ages ranged from 16 to 19. Most of the participants in this study were boarding students - they were accommodated in the school hostel, but apart from school holidays, the students had an opportunity to visit their families once a month. Their education and social-economic backgrounds varied. The environment in which these students learned were also diverse, in terms of the teaching and learning materials, teaching personnel, and classroom sizes, which primarily ranged from 30 to 45 students per class.

\section{Procedure}

Permission to conduct this qualitative study was granted by the regional educational directors via the relevant authorities in the Ministry of Education, Sport, and Culture. Twenty-three public high schools in the northern regions (Omusati, Oshana, Oshikoto, and Ohangwena) of the country, where a large proportion of students come from, were randomly selected to participate in this study. All the approached schools accepted the request to participate in this study (10 situated in urban, 8 in semi-urban, and 5 in rural areas). The mathematics teachers selected five students from each school, namely students who were observed to be having difficulties in learning grade 11 mathematics. Furthermore, gender balance was considered per school. The students were informed in advance by the author about the study procedures, their 
Students' desires for high-level teaching and learning opportunities: Views of Namibian

Grade 11 students observed to have difficulties in learning mathematics

S. T. Hamukwaya

rights to withdraw from the study if desired, and measures for maintaining confidentiality and anonymity. In addition, the students were asked to voluntarily participate in the study; consent from all students was obtained in writing prior to the interview.

\section{Data collection}

The data collection was performed via face-to-face semi-structured interviews to allow students to provide their own thoughts and opinions regarding what causes learning grade 11 mathematics to be difficult. The author conducted the interviews in September 2018 at the participants' schools. The time taken for each interview varied depending on the students' responses, but most students took half an hour. The interviews were audio recorded. The students responded in the language they were comfortable with, either English or Oshiwambo, the students' native language. The author is native in Oshiwambo and was able to prompt further questions for clarification in both languages and transcribe and analyse the data. A general interview framework consisting of nine unstructured questions guided the discussion (see Appendix A). The framework allowed the interviewer to maintain a focus without imposing other general questions (Elliott, \& Timulak, 2005).

\section{Data analysis}

The study adopted an interpretational data analysis, whereby the author attempted to examine and understand the transcripts to determine common themes which could be categorised based on students' views of what caused them to consider they were not having difficulties in learning mathematics. The interviews were transcribed by the author, and the recordings were played several times to ensure accuracy at the same time the notes were taken. The transcriptions were reread thoroughly, after which significant words and phrases were highlighted. Interesting features of the data were coded, excluding content unrelated to the aim of this study. Categories were generated, and the transcripts were reread alongside the categories. For validity and reliability purposes, the transcripts were shared with a researcher in the field for necessary input. The categories were further analysed, and reasons and factors that might influence students' views were identified and appear as the major findings of the study-why students did not believe they were having difficulties in learning mathematics.

\section{Findings}

This section presents the study findings based on the objective previously outlined in this paper. The students expressed their views based on their learning experience, and many were able to elaborate on them. Though students responded in the language in which they felt comfortable, it was difficult for some to provide an explanation, though this varied by question. These views were identified as the students' opinions and the factors that caused them to believe they were not having difficulties in learning mathematics. The findings are presented with the support of direct quotations as supportive claims.

\section{Students' views about learning grade 11 mathematics}

Table 1 presents a sample of how the analysis of the students' views was conducted. The left column contains the coding and categories used during the analysis process in addition to the number of responses. Meanwhile, the right column contains descriptions of the categories that emerged and formed the initial themes of the students' views. 
Table 1: Students' views about learning grade 11 mathematics

\begin{tabular}{cl}
\hline Coding and categories & Descriptions \\
\hline $\begin{array}{l}\text { 'Easy' to study; 'easy' to } \\
\text { understand; catch up 'easily' } \\
\text { (45 responses) }\end{array}$ & $\begin{array}{l}\text { The students found mathematics to be an easy subject to learn } \\
\text { and catch up in, and some found mathematics easy, yet they } \\
\text { failed. Mathematics was thought to be easy to understand, as it } \\
\text { requires only knowing formulas rather than memorisation or } \\
\text { summaries, as in other subjects. Mathematics was thought to only } \\
\text { require concentration from individual students, commitment, } \\
\text { more revision, and a desire to learn. It could be handled similarly } \\
\text { to other subjects - some believed that mathematics does not } \\
\text { require talent. }\end{array}$ \\
& $\begin{array}{l}\text { Mathematics is enjoyable and fun-students enjoyed making } \\
\text { calculations and feel good when performing them. They viewed } \\
\text { mathematics as a practical subject. Students enjoyed playing with } \\
\text { numbers. } \\
\text { (29 responses) }\end{array}$ \\
math 'enjoyable'; I 'enjoy' & $\begin{array}{l}\text { Mathematics is an interesting subject to study, and some students } \\
\text { wished to better understand it. }\end{array}$ \\
'Interesting' subject & $\begin{array}{l}\text { Mathematics is a favourite subject among students because some } \\
\text { received good teaching instructions, and some performed better }\end{array}$ \\
(17 responses) & in mathematics compared with other school subjects.
\end{tabular}

It is evident from Table 1 that students in this study voiced positive views regarding the learning of mathematics. The common themes which were derived from the interview transcripts indicated that the subject is easy, enjoyable, interesting, and their favourite. The students perceived mathematics as an easy subject and even attempted to learn it and seek to better understand it, even though some students admitted they do not perform well in the subject. They voiced that mathematics requires only effort and the understanding of formulas, with "no need for memorization'. Students further expressed that mathematics is enjoyable because it is a practical subject and is not confusing, unlike some other school subjects. A larger number of students believed they could do better in mathematics, but only if they 'concentrate' when the teacher is presenting a lesson, 'pay attention' in class, and be 'committed' to their studies. It is interesting to note that the students illustrated a desire to learn mathematics. In general, these findings suggest that if students exhibit positive views towards the learning of mathematics, this might positively impact their interest in the subject, and they might find it enjoyable and consider it their favourite subject.

\section{Factors influencing students' views}

Despite students expressed positive views about learning mathematics, they mentioned some factors believed to positively or negatively impact their learning. Their views on the factors that affects their learning of grade 11 mathematics are elaborated on in this section. These factors were separated into four themes as presented in Figure 1. 
Students' desires for high-level teaching and learning opportunities: Views of Namibian

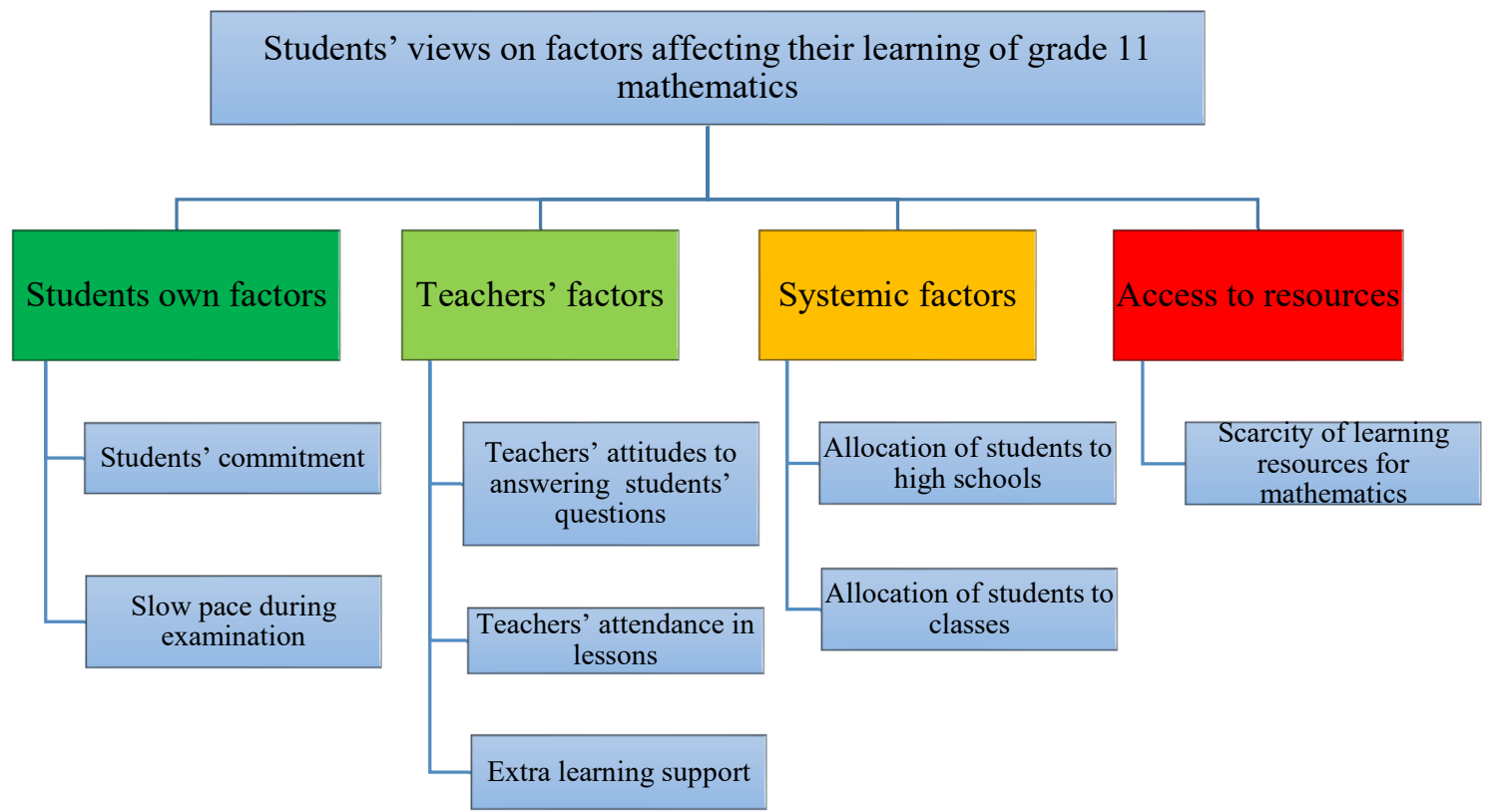

Figure 1 Students' views on factors affecting their learning of grade 11 mathematics

\section{Students' views on own factors (123 responses)}

Students' commitment Many students mentioned that they were not performing well in mathematics because they were 'not committed' and did not pay attention or could not concentrate in the classroom when the teacher was presenting a lesson. The impression was that students were aware that their own negative practices might have affected their learning; however, they said that commitment in learning mathematics is important. Based on the students' view, they understood that if they were not committed to studying mathematics, this might negatively impact their learning process and affect their performance in mathematics.

Slow pace during examinations Some students mentioned that they were not performing well in mathematics because they were slow when taking written examinations. In addition, they felt that the time allocated for writing examinations was insufficient, as it did not accommodate them. Some students viewed that the time does not correspond with the length of the examination paper and that this caused them to not be able to finish, resulting in their school assessment being negatively affected. Thus, students see a need to be given enough time for them to finish examination papers, as they tend to believe that if they had sufficient time, they may perform better. However, the findings indicate that the core students were mostly disadvantaged compare with those taking other levels.

\section{Students' views on teachers' factors (105 responses)}

Teachers' attitudes to answering students' questions A few students mentioned that they received positive support from their teachers: 'our teacher helps the individuals in class - those that don't understand'. Most reported that teachers did not attend to their questions positively. Students expressed that some teachers rejected students' questions when the students did not understand, especially when being taught quickly. According to the students' views, teachers would sometimes say, 'go and ask others', 'look at it yourself', or 'you are useless at this'. 
Due to these attitudes that mentioned about the teachers, students often opted to receive help from their friends. This indicates that if teachers do not respond to students' questions, the students will not obtain good learning opportunities, especially if their peers have failed to understand the concept as well. Thus, students are of the opinion that these negative attitudes affect their learning process.

Teachers' attendance in lessons Another view that emerged from the data was the poor attendance of teachers in their classes: 'absent too much'. Students mentioned that when a teacher was absent, the students were never given work to complete. Due to insufficient time to cover all the subject competencies, the teachers omitted some topics. Students expressed the view that in some instances, part of the previous examination was cancelled because the content had not been covered. Furthermore, some students believed that because of poor teachers' attendance in lessons, their assessment tasks were not marked properly: 'as soon he checks 2 or 3 books then he is done'. According to the students' perceptions, teachers spent an insufficient time in classes, causing students to have uncovered content and unmarked work. As a result, students' learning opportunities might have been affected. These views indicate that teachers often discouraged students from learning through their practices.

Extra learning support It was found from the interviews that extra classes were fully practical in only 2 of the 23 participating schools. Most of the students stated that those who opted for the extended levels received extra learning support. This was revealed by one student: 'We don't have extra classes except for extended people especially the grade $12 \mathrm{~s} . .$. '. According to another student, '...us the Grade 11 s we don't receive much attention at all...'. This appears to suggest that the core-level students in grade 11 felt they had no access to adequate learning support compared with those in grade 12 and those taking extended-level mathematics.

\section{Students' views about systemic factors (34 responses)}

Allocation of students to high schools Some students stated that some public schools are regarded as high-performing schools. According to the students, such schools admit only those students with high performance in grade 10, and most of them study either high or extended mathematics. Students believed that they were allocated to low-performing schools and did not have as much access to quality mathematics teaching or learning opportunities as the schools that were regarded as an 'excellent school'. Thus, students felt it would be beneficial if the students could be mixed so that they could help one another at school. The following quote illustrates these findings: 'Excellent schools should admit all students, not only those with good points. Like our school takes only those with low points from grade ten'.

Allocation of students to classes The issue of students' allocation to classes also emerged. Though students felt they were allocated to low-performing schools, most students expressed that the allocation of students into classes was again based on students' performance in grade 10. Students further expressed that those with good marks from grade 10 typically take mathematics at the extended level in a separate class. A quote from one student illustrates this finding: 'At our school, those of us with 23 points are in a separate class, [...]. I understand this is done as those with higher points will take extended level'. On the other hand, some students believed it would be better if all students could take only extended-level mathematics and thereby avoid grouping students based on their previous performance. However, some students believed this allocation is done to simplify teaching for teachers regarding class activities for the core and extended levels. Nonetheless, the core-level students believed they were not receiving as high a level of teaching and learning as those allocated to extended classes. 
Students' desires for high-level teaching and learning opportunities: Views of Namibian

Grade 11 students observed to have difficulties in learning mathematics

S. T. Hamukwaya

Views on access to resources (13 responses)

Scarcity of learning resources for mathematics

Of the 23 schools that participated in this study, only 1 school voiced the opinion that they had enough textbooks for its students. In the other schools, the students were forced to share textbooks, and a quote from one student supports this finding: 'We don't have enough mathematics cosmetics. [...] only for those who are doing a higher level...'. Meanwhile, another student said, 'We share the textbooks 5 per book...'. In some schools, students were told '...to wait for the grade $12 \mathrm{~s}$ to complete their examination then we can get textbooks from them'. These views illustrated that the number of textbooks was insufficient in the participating schools. In addition to this, students tended to believe that those who were taking ordinary mathematics were the most affected, especially in grade 11 . This suggests that the distribution of textbooks prioritised $12^{\text {th }}$ graders. The students considered textbooks to be important to their learning, and the students felt they did not have enough access to teaching and learning resources, which they believed might have affected their academic performance.

\section{Discussion}

The study noted the students' desire for high-level access to teaching and learning opportunities. The students' perceptions of those factors believed to have influenced the learning of the grade 11 students at 23 Namibian high school were investigated. The results presented in Table 1 illustrate that students perceive mathematics to be an easy and favorable subject, and found it to be interesting and enjoyable. These findings contrast with much of the research conducted in the field that tend to report that students find mathematics difficult and uninteresting (e.g. Eshun-Famiyeh, 2005; Mundia, 2010; Sarsani \& Maddini, 2009). The students viewed that for mathematics, as a practical subject, they only needed to understand the rules and procedures that were necessary to be followed in performing calculations.

Nevertheless, although the students felt comfortable with the subject and perceived learning mathematics in a positive way, the study illustrates practical issues and factors that hinder the students' learning of mathematics, as presented in Fig1. These factors are believed to explain why students believed that they had no difficulties in learning mathematics. The study found that most of the students acknowledged they were not committed to learning mathematics, thus causing some to achieved low scores on their mathematics assessments. The amount of time allocated for examination was also revealed to not correlate with the length of the examination paper, preventing students from finishing and causing them to have a poor school assessment. Interestingly, students indicated a desire to learn mathematics and a wish to better understand it. According to the students' views, concentration and paying attention during the lesson were the most important aspects mentioned in order for students to be successful at learning mathematics.

The study further indicates that few students received positive responses from their teachers whenever they asked questions and required clarity. Other students viewed that some teachers demoralise them with negative responses when replying to their questions through the use of antisocial remarks. The study demonstrated that due to the negative practices and attitudes of teachers, students opt to ask for help from their peers when they do not understand the subject material. This suggests that if teachers do not respond to students positively, then students will not have a proper opportunity to learn mathematics. Based on this study, teachers' practices can cause students to have poor access to learning opportunities if they do not understand a topic in mathematics. These findings therefore encourage and challenge the teachers to create a conducive learning environment if students ask questions when they do not understand. 
Another view revealed from the study is the insufficient time spent in classes by teachers. This was found to be one of the teachers' factors that negatively affected the students' learning of mathematics. According to the students' views, some teachers were often absent from classes, hindering them from having sufficient time to cover the syllabus. The students appeared to believe that without sufficient time for teaching, their learning opportunities might be negatively affected. This might contribute to a lack of learning opportunities, as it appears impossible to learn mathematics without relevant access to learning opportunities, which thus contributes to their failure.

Furthermore, there were only a few students that stated that their teachers provided them with the necessary learning support they needed. In contrast, many students who were taking corelevel mathematics alleged that they were not receiving such support, which was allocated to those in grade 12 and those who were studying extended-level mathematics. These perspectives suggest vast difference among teachers when providing extra learning support to extended- and core-level students. Furthermore, it reflects the positive and negative evaluations that arise from students in relation to their level of studying mathematics and receiving support. This illustrates that there were few supporting learning opportunities for core-level students, which may serve as an obstacle to students in acquiring a deeper understanding of the subject.

Another emergent factor from the study were the school systemic factors, which appear to significantly influence students' learning (Tsanwani et al., 2014). The students in this present study mentioned their allocation to classes or schools, and they appeared to believe that those taking mathematics at the extended level were receiving good mathematics teaching and learning, similar to students attending 'excellent schools'. However, some students believed that the division simplifies teaching for teachers; while other students believed they did not have access to high-level mathematics teaching or learning opportunities, as they were placed in classes or schools based on their previous academic performance. Evidence from the students' perceptions reveals that due to this allocation, the students were exposed to different types of teaching and learning instruction. Based on the students' opinions, an association exists between the students' performance in mathematics and the classroom or school allocation. These views present differences regarding the quality of teaching and learning that occurs base on the students' perceptions.

Based on students' views in this study, having access to learning resources is crucial to enhance their understanding (Enu et al., 2015). It was revealed in the study that only 1 of the 23 participating schools had students who related that textbooks were not shared; meanwhile, in the other schools, the students stated that textbooks were shared. However, those students also asserted that those who were taking higher- or extended-level mathematics had enough textbooks. Based on these findings, a difference in the distribution of textbooks in some high schools in Namibia is highlighted, especially for core-level students. Importantly, the students in this study tend to believe that their learning might be affected if they do not have access to sufficient textbooks.

\section{Conclusion and Recommendations}

The study considered the different views of students and their justifications. A general perception from this study was that 'mathematics is an easy subject' and that the students wished to understand it better despite the influencing factors affecting their learning; this was a significant message revealed by students who were observed to have difficulties in learning mathematics. Given this view, it would be advantageous for the teachers also to be interviewed on the criteria used for their identification of students. This was a limitation in this study, as interviews with teachers were not conducted. Thus, a follow-up study is necessary. 
Students' desires for high-level teaching and learning opportunities: Views of Namibian

Grade 11 students observed to have difficulties in learning mathematics

S. T. Hamukwaya

Students appeared to believe that factors such as school or class allocation, teachers' attitudes, their own (students') commitment, and the shortage of learning resources affected their learning process. For students, based on their views, the consequences of these factors were clear: If they have no access to relevant teaching and learning opportunities, their learning will be affected. Though some students recognised they were not successful in mathematics, they did not believe it was because they had difficulties in learning mathematics. Given these views, the study showed a difference that could be explained by systemic factors and additional learning support or access to appropriate learning facilities/teaching aids compared with their counterparts: those taking extended-level mathematics or those at excellent schools. The importance of relevant access to teaching and learning was observed in this study. Therefore, some implications of this study, based on students' views, are indicated below as recommendations:

- The allocation of students to high schools and classes should consider students with diverse learning abilities; since students allocated to low-performance schools or classrooms tended to believe that they did not have access to high-level teaching or learning opportunities.

- There is a need to provide sufficient instructional materials for all students, regardless of the mathematics level they are studying.

- Teachers should improve their attendance at core-level lessons in order to have enough time to teach and support students' learning.

- Extra learning support should be available for everyone and not only $12^{\text {th }}$ graders or to those studying mathematics at an abstract level.

- Core-level students should be provided with quality of learning activities that other students have.

The results of this study can benefit other schools in Namibia that were not part of this study as well as regions with similar socio-cultural settings and practices to those presented in this paper. Although the students' views were based on their experience of learning in a curriculum soon to be phased-out, the author believes that some basic information may still be valid for understanding students' views in learning mathematics and the factors that influence such views. With this information, teachers should be able to provide better teaching and learning processes for all students.

\section{References}

Agudelo-Valderrama, A. C. (1996). Improving mathematics education in Colombian schools: 'Mathematics for all'. International Journal of Educational Development, 16(1), 15-26.

Ampadu, E. (2013). Aspiring Mathematicians: Students' Views Regarding What it takes to be Successful in Mathematics. International Journal for Mathematics Teaching \& Learning. 31(1), 53-60.

Bol, L., \& Berry, R. Q. (2005). Secondary mathematics teachers' perceptions of the achievement gap. The High School Journal, 88(4), 32-45.

Buehl, M. M., \& Alexander, P. A. (2005). Motivation and performance differences in students' domain-specific epistemological belief profiles. American Educational Research Journal, 42(4), 697-726. 
Coştu, S., Aydın, S., \& Filiz, M. (2009). Students' conceptions about browser-game-based learning in mathematics education: TTNetvitamin case. Procedia-Social and Behavioral Sciences, 1(1), 1848-1852.

De Corte, E., Op t Eynde, P., \& Verschaffel, L. (2002). "Knowing what to believe": The relevance of students' mathematical beliefs for mathematics education. In B.K Hofer \& P.R. Pintrich (Eds.), Personal epistemology: The psychology of beliefs about knowledge and knowing (pp. 297-320). Mahwah: Lawrence Erlbaum Associates Publishers.

Elbers, E. (2003). Classroom interaction as reflection: Learning and teaching mathematics in a community of inquiry. Educational Studies in Mathematics, 54(1), 77-99.

Elliott, R., \& Timulak, L. (2005). Descriptive and interpretive approaches to qualitative research. In J. Miles \& P. Gilbert (Eds.), A handbook of research methods for clinical and health psychology, 1(7), 147-159.

Enu, J. A. O. K., Agyman, O. K., \& Nkum, D. (2015). Factors influencing students' mathematics performance in some selected colleges of education in Ghana. International Journal of Education Learning and Development, 3(3), 68-74.

Eshun-Famiyeh, J. (2005). Early number competencies of children at the start of formal education. African Journal of Educational Studies in Mathematics and Sciences, 3(1), 2133.

Fleisch, B. (2008). Primary education in crisis: Why South African schoolchildren underachieve in reading and mathematics. Cape Town: Juta and Company Ltd.

Gafoor, K. A., Kurukkan, A. (2015). Learner and teacher perception on difficulties in learning and teaching mathematics. Paper presented at the National Conference on Mathematics Teaching: Approaches and Challenges, Regional Institute of Education, (Mysuru, Karnataka, India, Dec 21-22, 2015).

Hoyles, C. (1982). The pupil's view of mathematics learning. Educational Studies in Mathematics, 13(4), 349-372.

Jones, K. (2000). The student experience of mathematical proof at university level. International Journal of Mathematical Education in Science and Technology, 31(1), 53-60.

Makgato, M. (2007). Factors associated with poor performance of learners in mathematics and physical science in secondary schools in Soshanguve, South Africa. Africa education review, 4(1), 89-103.

McLeod, D. B. (1994). Research on affect and mathematics learning in the JRME: 1970 to the present. Journal for research in Mathematics Education, 25(6), 637-647.

McLeod, D. B. (1992). Research on affect in mathematics education: A reconceptualization. In D. A. Grouws (ED.), Handbook of research on mathematics teaching and learning, (pp. 575-596). New York: Macmillan.

Mundia, L. (2010). Problems in learning mathematics: Comparison of Brunei junior high school students in classes with and without repeaters. Journal of Mathematics Research, 2(3), 150-160.

Ponte, J. P., Matos, J. F., Guimarães, H. M., Leal, L. C., \& Canavarro, A. P. (1994). Teachers' and students' views and attitudes towards a new mathematics curriculum: A case study. Educational Studies in Mathematics, 26(4), 347-365. 
Students' desires for high-level teaching and learning opportunities: Views of Namibian

Grade 11 students observed to have difficulties in learning mathematics

S. T. Hamukwaya

Roesken, B., Hannula, M. S., \& Pehkonen, E. (2011). Dimensions of students' views of themselves as learners of mathematics. ZDM, 43(4), 497-506.

Sarsani, M. R., \& Maddini, R. (2009). Learning Difficulties in Mathematics (LDM) of Secondary School Students With Respect to Their Personal And Background Variables. $i$ Manager's Journal on Educational Psychology, 2(4), 85.

Schoenfeld, A. (1985). Mathematical problem solving. Orlando: Academic Press.

Schommer-Aikins, M. (2004). Explaining the epistemological belief system: Introducing the embedded systemic model and coordinated research approach. Educational Psychologist, 39(1), 19-29.

Sedig, K. (2008). From play to thoughtful learning: A design strategy to engage children with mathematical representations. Journal of Computers in Mathematics and Science Teaching, 27(1), 65-101.

Siyepu, S. (2013). The zone of proximal development in the learning of mathematics. South African Journal of Education, 33(2), 1-13.

Stodolsky, S. S., Salk, S., \& Glaessner, B. (1991). Student views about learning math and social studies. American Educational Research Journal, 28(1), 89-116.

Tsanwani, A., Harding, A., Engelbrecht, J., \& Maree, K. (2014). Perceptions of teachers and learners about factors that facilitate learners' performance in mathematics in South Africa. African Journal of Research in Mathematics, Science and Technology Education, 18(1), 4051.

Wong, N. Y., Lam, C. C., Wong, K. M. P., Leung, F. S., \& Mok, I. C. (2001). Students' views of mathematics learning: a cross-sectional survey in Hong Kong. Education Journal-Hong Kong-Chinese University of Hong Kong-, 29(2), 37-60. 